\title{
Laparoscopic versus open Varicocelectomy: An Observational Study
}

\author{
${ }^{1}$ Shaukat Jeelani, ${ }^{2}$ Atif Naeem, ${ }^{3}$ Ishfaq A Gilkar, ${ }^{4}$ Javid A Peer, ${ }^{5}$ Umer Mushtaq
}

\section{ABSTRACT}

Background: Varicocele is a collection of abnormally dilated, tortuous veins. A clinical varicocele is found in about $15 \%$ of all adult males, up to $35 \%$ of men who present for infertility evaluation and as many as $81 \%$ of men with secondary infertility, with a marked left-sided predominance. It is the most common correctable cause of male infertility.

Methodology: This study was conducted in the postgraduate department of surgery, Government Medical College, Srinagar for 2 years from December 2010 till May 2013. This was a prospective study and a total of 100 patients with clinically significant varicocele were included in this study. Patients were divided into two groups. Group A comprised of 50 patients who underwent open surgery, and group B comprised of 50 patients who underwent a laparoscopic approach.

Results: In our series of 100 patients, the minimum age was 10 and maximum was 50 years, eighty six had scrotal pain, 81 had testicular swelling and 25 patients presented with infertility, the operation time for laparoscopic varicocelectomy 48 minutes (mean) and in open surgery was 57 minutes (mean), We observed that postoperative analgesic requirement was almost equal in both groups,average hospital stay of 35.6 hours and 50.6 hours were observed in laparoscopic and open groups respectively.

Conclusion: In our study of 100 patients it was observed that the results of laparoscopic varicocelectomy were comparable to open technique with minimum morbidity, shorter hospital stay and with the advantage of treating bilateral varicoceles without any additional incisions. Also, laparoscopic varicocelectomy produces better overall patient satisfaction and hence can be considered as a preferred surgical technique although sperm analysis results were the same in both methods.

Keywords: Laparoscopic, Infertility, Varicocelectomy.

How to cite this article: Jeelani S, Naeem A, Gilkar IA, Peer JA, Mushtaq U. Laparoscopic versus open Varicocelectomy: An Observational Study. World J Lap Surg 2018;11(2):76-80.

Source of support: Nil

Conflict of interest: None

\footnotetext{
${ }^{1} \mathrm{HOD},{ }^{2-5}$ Senior Resident

${ }^{1-5}$ Department of General Surgery, Government Medical College Srinagar, Jammu and Kashmir, India
}

Corresponding Author: Ishfaq A Gilkar, Senior Resident, Department of General Surgery, Government Medical College Srinagar, Jammu and Kashmir, India. e-mail: drishfaqahmedgilkar @rediffmail.com

\section{INTRODUCTION}

Varicocele is a collection of abnormally dilated, tortuous veins. ${ }^{1}$ A clinical varicocele is found in about $15 \%$ of all adult males, up to $35 \%$ of men who present for infertility evaluation, and as many as $81 \%$ of men with secondary infertility, with a marked left-sided predominance. ${ }^{2-4}$ It is the most common correctable cause of male infertility. Several non-randomized studies have suggested that repairing a clinically palpable varicocele in the presence of abnormal semen analysis results in improvement of parameters and pregnancy rates. As most adolescent varicoceles are asymptomatic and many are discovered on routine physical examination, therefore true incidence of varicocele is much higher than expected. The introduction of radiographic diagnostic studies and scrotal ultrasound has allowed for improved diagnosis and further characterization of varicocele. According to the criteria proposed by the World Health Organization (WHO 19853), ${ }^{3}$ varicoceles are categorized as grade I-when the impulse of dilated veins appear over scrotal skin with Valsalva maneuver but without venous tortuosity. Grade II-when a palpable tortuosity and an impulse are found with Valsalva maneuver. Grade III-when a palpable tortuosity without abdominal straining is noted during the physical examination.

Different approaches have been applied for the treatment of varicocele including open surgery, sclerotherapy and, recently, laparoscopy. In this study, we evaluated and compared the operative time, sperm parameters and complications in the postoperative period between laparoscopic and conventional methods for high open ligation of varicocele.

\section{METHODOLOGY}

This study was conducted in the postgraduate department of surgery, Government Medical College Srinagar for 2 years from December 2010 till May 2013. This was a prospective study and a total of 100 patients with clinically significant varicocele were included in this study. Patients were divided into two groups. Group A comprised of 50 patients who underwent laparoscopic surgery and group B comprised of 50 patients who underwent an open approach. Majority of patients were in the age group ranging from 12 years to 36 years (average 24 years) 
in Group A and 10 years to 36 years (average 23 years) in group B. Majority of patients presented with complaints of swelling in the left hemiscrotum, detected incidentally. Dragging sensation in the scrotal region was the second most common complaint. Few of the patients who were above 25 years of age presented with primary or secondary infertility. The diagnosis was established mainly by clinical examination and scrotal ultrasound. Majority of patients had a unilateral varicocele (77\% in Group A and $79 \%$ in Group B). The diagnosis was confirmed by Doppler in all cases. Semen analysis was performed in patients presenting with infertility at least twice preoperatively and every 6 months postoperatively for 18 months.

\section{SURGICAL TECHNIQUE}

\section{Laparoscopic Varicocelectomy}

Patients were operated in supine position under general anesthesia. A urinary catheter was inserted after the induction of anesthesia to evacuate the bladder or the patient was asked to void just before shifting to the operation room. Post induction nasogastric tube was passed to decompress the stomach. A veress needle for the creation of pneumoperitoneum was introduced through a small infra-umbilical incision. Then, the abdomen was inflated with $\mathrm{CO}_{2}$ gas, the pressure maintained between $12-14 \mathrm{~mm} \mathrm{Hg}$. The head end of the bed was lowered 150 to 300 to displace the bowel away from the lower quadrants of the abdomen. Veress needle was replaced by $10 \mathrm{~mm}$ trocar and cannula after enlarging the skin incision. $10 \mathrm{~mm}$ telescope was inserted through the $10 \mathrm{~mm}$ trocar. Under direct vision, 2nd and 3rd trocars (10 $\mathrm{mm}$ and $5 \mathrm{~mm}$ ) were bilaterally introduced through the incisions located in the 2/3rd distance from umbilicus to anterior superior iliac spine. Grasper and scissors were used to put two perpendicular incisions into the peritoneum overlying the internal spermatic veins. The vascular mass was lifted to separate arterial and lymphatic components

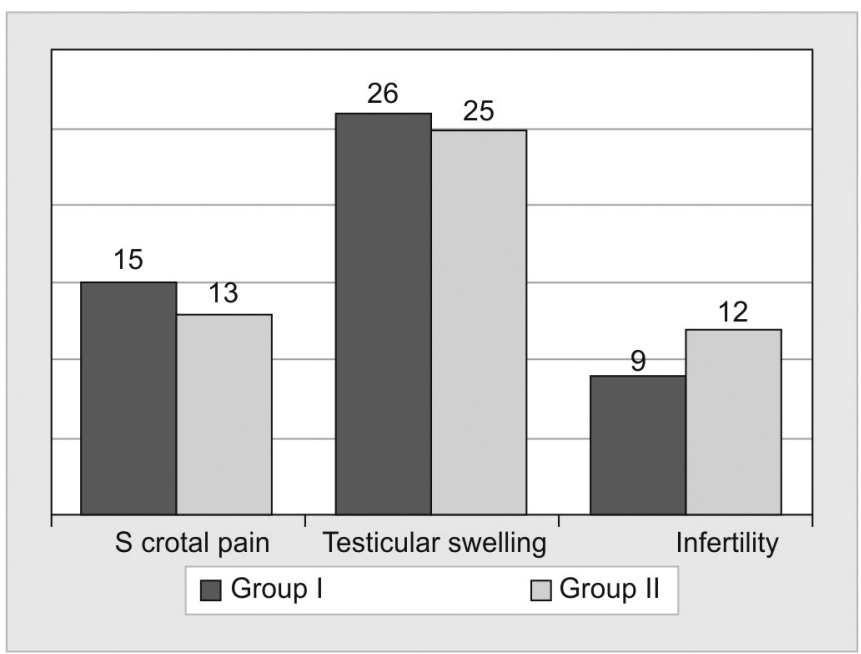

Graph 1: Presentation in both groups from the veins. Then, the veins were ligated by clips or by intracorporeal knotting. After verifying the hemostasis, trocars were removed and incision sutured. Antiseptic laparoscopic dressings were applied.

\section{Open Surgery}

Open high ligation of testicular veins was done under spinal or general anesthesia. A small muscle splitting incision made at the level of the anterior superior iliac spine, and the retroperitoneal space was entered, with the peritoneal envelope swept medially to identify the internal spermatic vessels. These vessels were ligated and divided. Great care was taken to preserve testicular artery. The external spermatic fascia was sutured, and the wound was closed in layers. The antiseptic dressing was applied.

\section{AIM AND OBJECTIVES}

To compare the outcome of laparoscopic with open varicocelectomy in terms of;

- Operative time.

- Complications.

- Improvement in semen analysis after 3 months.

- Analgesic requirement.

- Hospital stay.

\section{RESULTS}

Group A consisted of 50 patients who underwent laparoscopic varicocelectomy; indications for varicocelectomy were the same in all groups and included infertility, scrotal pain, and documented abnormalities in sperm parameters (Graph 1).

The operation time was calculated from trocar insertion to trocar extraction and skin closure for laparoscopic varicocelectomy, and from incision to skin closure in open varicocelectomy (Graph 2).

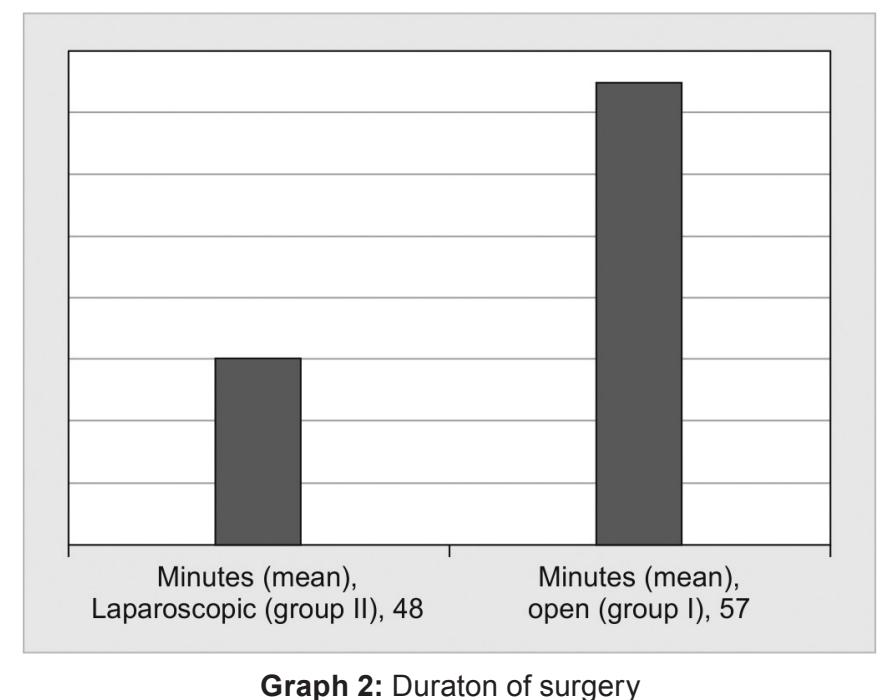




\section{Intraoperative Complications}

In both the groups, no vascular or intestinal complications occurred. Conversion from laparoscopic to open approach due to hemorrhage or other causes did not occur either.

\section{Postoperative Complications}

Six patients in laparoscopic and eleven patients in open surgery suffered from persistent pain, one in group A and one patient in group B developed scrotal edema, five patients in group B and three in group A developed hydrocele which was treated by rest, nonsteroidal antiinflammatory drugs, and scrotal supports. Recurrence was more in group B, and the patients underwent open Varicocelectomy under GA. No hernias occurred after laparoscopic varicocelectomy. In group A, there were 6 patients with wound infection, all of which were managed by medical therapy (Graph 3 ).

\section{DISCUSSION}

There are different surgical methods for varicocele treatment. The first surgical method for varicocele was explained by Celsus in the first century (ipsilateral orchidectomy which consisted of an atrophic testis). ${ }^{5}$ The technique of laparoscopic varicocelectomy has gained wide acceptance since its introduction by Winfield and his colleagues in $1991 .{ }^{6}$ Reports have suggested that laparoscopic approach not only carried lesser morbidity, less postoperative pain, early return to routine work but also had the same success rate as open procedures.

The most effective and least invasive method is yet unknown. We compared open varicocelectomy under GA with the laparoscopic approach. We found that although the two methods had comparable results, regarding and complications and laparoscopic method was not superior.

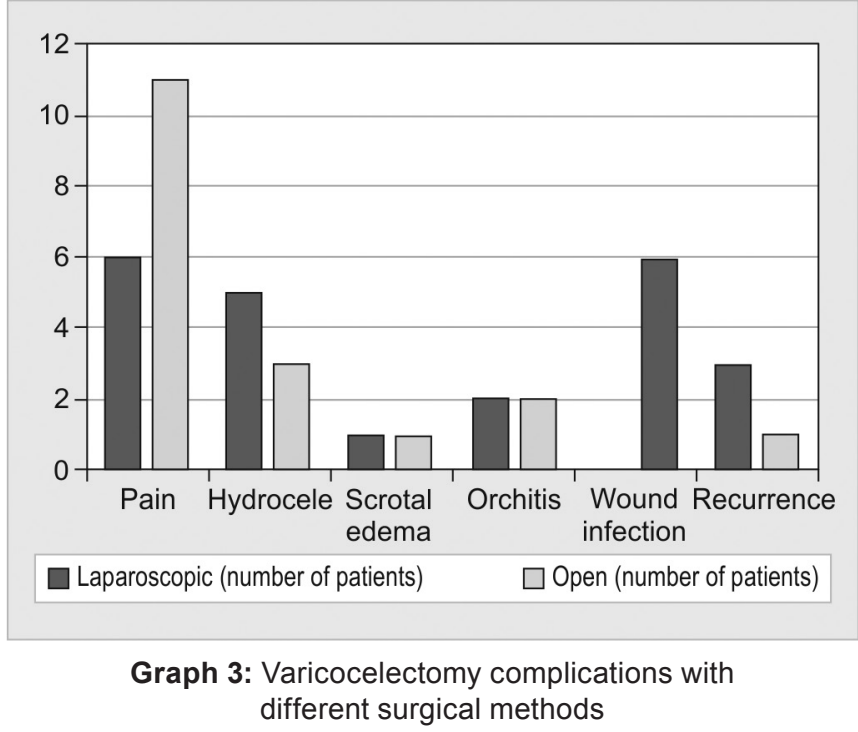

The fear of disfiguring scar, prolonged hospital stay, the double incision for bilateral varicocele and associated prolonged postoperative pain and the longer duration to return to normal activity had been the major concern of most of the patients undergoing open varicocelectomy.

In our series of 100 patients the minimum age was 10 and maximum was 50 years (Table 1) in a comparative study conducted by Bebars et al. the age of patients in laparoscopic group was 8-39 years (mean 21.3) and it was 8-42 years (mean 24.4) in open varicocelectomy group.? Lynch WJ et al. reported the age range of patients in open group 25-48 years and in the laparoscopic group it was $23-49$ years. $^{8}$ Age group of $16-54$ years was reported by Hagood. ${ }^{9}$

In our study of 100 varicoceles patients, 86 had scrotal pain, and eighty one had testicular swelling and 25 patients presented with infertility (Graph 1 and Table 2) similar observations were made by Al-Shareef et al. ${ }^{10}$ and reported that in 26 varicoceles who were treated by laparoscopic ligation of internal spermatic veins under general anesthesia. Twenty-one patients had either scrotal discomfort or painful swelling and four patients presented with infertility.

The operation time was calculated from trocar insertion to trocar extraction and skin closure for laparoscopic varicocelectomy 48 minutes (mean) and in open surgery was 57 minutes (mean) (Graph 2 and Table 3). The average operating time for laparoscopic varicocelectomy after the training period has been completed was 44 minutes in series by Garridoa et al. ${ }^{11}$ In a study by Matsuda et al., the operating time for laparoscopic varicocelectomy reported was 35-135 minutes (mean 85 minutes). ${ }^{12}$

In our study instead of demand analgesic, we gave every patient in both the groups, injection diclofenac sodium on 12 hourly bases to make patients pain free on the day of surgery. However, from the 1st postoperative day, it was given on demand. We observed that

Table 1: Age distribution of patients in our study

\begin{tabular}{lllll}
\hline \multirow{2}{*}{$\begin{array}{l}\text { Age in } \\
\text { years }\end{array}$} & \multicolumn{3}{c}{ Group A } & \multicolumn{2}{c}{ Group B } \\
\cline { 2 - 5 } & No. & Percentage (\%) & No. & Percentage (\%) \\
\hline $10-19$ & 10 & 20 & 12 & 24 \\
$20-29$ & 27 & 54 & 22 & 44 \\
$30-39$ & 11 & 22 & 9 & 18 \\
$40-49$ & 2 & 4 & 7 & 14 \\
\hline Total & 50 & 100 & 50 & 100 \\
\hline
\end{tabular}

Table 2: Presentation in both groups

\begin{tabular}{lllll}
\hline & \multicolumn{3}{c}{ Group A } & \multicolumn{2}{c}{ Group B } \\
\cline { 2 - 5 } Presentation & No. & Percentage (\%) & No. & Percentage (\%) \\
\hline Scrotal pain & 15 & 30 & 13 & 26 \\
Testicular & 26 & 52 & 25 & 50 \\
swelling & & & & \\
Infertilitty & 9 & 18 & 12 & 24 \\
\hline
\end{tabular}


Table 3: Duration of surgery

\begin{tabular}{ll}
\hline Laparoscopic (Group B) & 48 minutes (mean) \\
Open (Group A) & 57 minutes (mean) \\
\hline
\end{tabular}

the postoperative analgesic requirement was almost equal to available series in the literature recurrence was observed in one patient during the follow-up period. Shamsa et al. ${ }^{13}$ reported recurrence in $2(6.7 \%)$ patients of the laparoscopic group, but it was not observed in patients who underwent open varicocelectomy. Watanabe et al. reported $6.1 \%$ recurrence in 33 patients with bilateral laparoscopic varicocelectomy. They mentioned a recurrence rate of $12 \%$ in 50 patients with unilateral varicocelectomy by high retroperitoneal method. ${ }^{14}$

The hydrocele is another complication of varicocelectomy (Graph 3, Table 4). The incidence of this complication is $0.3 \%$ to $40.4 \%$ as reported by Kočvara et al. ${ }^{15}$ Etiology of post varicocelectomy hydrocele is ligation of the lymphatic vessels that are colorless and sometimes are mistaken for veins. ${ }^{16}$

The improvement in the quality of semen was analyzed and compared with the pre-operative semen analysis (Tables 5 and 6). Preoperative semen analysis was done 1 week before surgery, and then postoperative semen analysis was advised 3 months after varicocelectomy. In the present series, we found that the mean improvement in sperm concentration was 8.9 million $/ \mathrm{mL}$. The mean percentage of improvement in sperm motility was approx. $5.5 \%$. The average decrease in abnormal forms

Table 4: Varicocelectomy complications with different surgical methods

\begin{tabular}{lll}
\hline Complication & $\begin{array}{l}\text { Laparoscopic } \\
\text { (number of patients) }\end{array}$ & C \\
\hline Pain & 6 & 11 \\
Hydrocele & 5 & 3 \\
Scrotal edema & 1 & 1 \\
Orchitis & 2 & 2 \\
Wound infection & 0 & 6 \\
Recurrence & 3 & 1 \\
\hline
\end{tabular}

Table 5: Semen analysis results with different varicocelectomy methods

\begin{tabular}{lll}
\hline Laparoscopic & & \\
Varicocelectomy & Before treatment & After treatment \\
\hline Sperm count $\times 106 / \mathrm{ml}$ & $52 \pm 36$ & $44 \pm 30$ \\
Sperm motility $\%$ & $70 \pm 50$ & $88 \pm 80$ \\
Sperm morphology $\%$ & $60 \pm 50$ & $77 \pm 35$ \\
\hline
\end{tabular}

Table 6: Semen analysis results with different varicocelectomy methods

\begin{tabular}{lll}
\hline Open Varicocelectomy & Before treatment & After treatment \\
\hline Sperm count, $\times 106 / \mathrm{ml}$ & $46 \pm 33$ & $40 \pm 36$ \\
Sperm motility \% & $47 \pm 33$ & $60 \pm 42$ \\
Sperm morphology \% & $44 \pm 39$ & $51 \pm 22$ \\
\hline
\end{tabular}

was 5\%. Similarly, Gouda El-labban ${ }^{6}$ reported significant improvement in semen parameters in both laparoscopic and open groups. Al-Kandari et al. found that improvement in sperm motility and/or concentration was comparable and observed in $65 \%, 67 \%$, and $76 \%$ of the open, laparoscopic, and micro-surgical groups, respectively. Also, the pregnancy rate at 1 year was not significantly different and was $28 \%, 30 \%$, and $40 \%$ in the three groups respectively. ${ }^{16}$

We observed that in the laparoscopic group an average hospital stay of 35.6 hours which was significantly less than the open surgical group with an average hospital stay of 50.6 hours (Graph 4 and Table 7). Gouda El-labban ${ }^{6}$ in his comparative study observed that patients in open varicocelectomy stayed in the hospital much longer than the laparoscopic group with an average of 3 days versus 1.5 days respectively. Osman et al. reported that the postoperative hospital stay was 52 hours and 8.4 hours in open and laparoscopic varicocelectomy group respectively. ${ }^{17}$ Podkamenev et al. reported average hospital stay of 3 days for laparoscopic varicocelectomy versus 7 days for open varicocelectomy ${ }^{18}$ Similarly, Bebars et al. observed longer postoperative hospital stay in open as compared to laparoscopic varicocelectomy group and it was 3.5 (2-8) days versus 1.3 (1-3) days. ${ }^{7}$ Ogura et al. also observed the shorter length of hospital stay for the laparoscopic patients than for the open surgery group (0.97 vs 1.42 days, $\mathrm{p}=0.0078) .{ }^{19}$ Zain H Al-Sharief et al. in their series reported hospital stay of 2 days versus 5 days in laparoscopic varicocelectomy and open varicocelectomy,

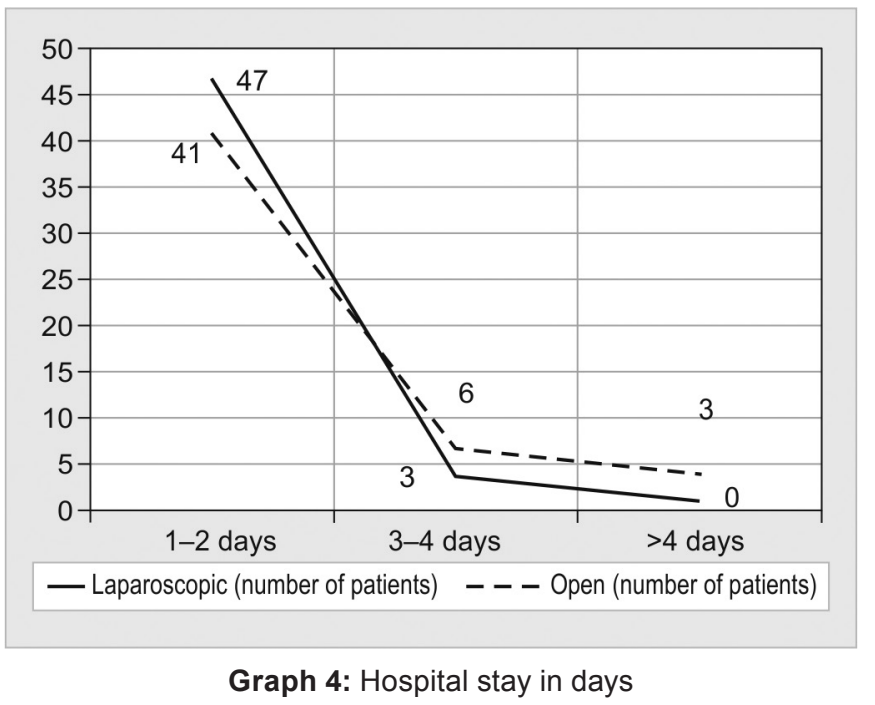

Table 7: Hospital stay in days

\begin{tabular}{lll}
\hline Hospital stay & $\begin{array}{l}\text { Laparoscopic } \\
\text { (number of patients) }\end{array}$ & $\begin{array}{l}\text { Open } \\
\text { (number of patients) }\end{array}$ \\
\hline $1-2$ & 47 & 41 \\
$3-4$ & 3 & 6 \\
$>4$ & 0 & 3 \\
\hline
\end{tabular}


respectively. In our series postoperative stay was comparable to other available series in the literature. It was observed that patients who were from city or nearby areas happily accepted early discharge from the hospital, whereas some patients from far-flung areas were mentally unprepared to get their discharge early. It was experienced that there was a need to motivate and tell patients about the real benefits of laparoscopic varicocelectomy including early discharge from the hospital.

\section{CONCLUSION}

In our study of 100 patients, it was observed that the results of laparoscopic varicocelectomy were comparable to open technique with minimum morbidity, shorter hospital stay and with the advantage of treating bilateral varicoceles without any additional incisions. Also, laparoscopic varicocelectomy produces better overall patient satisfaction and hence can be considered as a preferred surgical technique although sperm analysis results were the same in both methods.

\section{REFERENCES}

1. Choi WS, Kim SW. Current issues in varicocele management: a review. World J Mens Health. 2013 Apr;31(1):12-20.

2. Clarke BG. Incidence of varicocele in normal men and among men of different ages. JAMA. 1966 Dec 5;198(10):1121-1122.

3. Gorelick JI, Goldstein M. Loss of fertility in men with varicocele. Fertil Steril. March 1993;59:613-616.

4. Alsaikhan B, Alrabeeah K, Delouya G, Zini A. Epidemiology of varicocele. Asian journal of andrology. 2016 Mar;18(2): 179-181.

5. Dubin L, Amelar RD. Varicocele. Urol Clin North Am. 1978;5:563-572.

6. Hargreave TB. Varicocele: A clinical enigma. Br J Urol. 1993 Oct;72(4):401-408.

7. Bebars GA, et al. Laparoscopic versus open high ligation of the testicular veins for the treatment of varicocele. JSLS. 2000 Jul-Sep; 4(3): 209-213

8. Lynch W J, Badenoch D F and Mcanena O J Comparison of Laparoscopic and open ligation of the testicular veins. British Journal of Urology dec 1993;72:796-798.
9. Hagood PG, Mehan DJ, Worischeck JH, et al. Laparoscopic varicocelectomy: preliminary report of a new technique. J Urol Jan1992;147:73-76.

10. Al-Shareef ZH, Koneru SR, Al-Tayeb A, Shehata ZM, Aly TF, Basyouni A. Laparoscopic ligation of varicoceles: an anatomically superior operation. Annals of the Royal College of Surgeons of England. 1993 Sep;75(5):345-348.

11. Jiménez AG, de la Torre García MV, de Badajoz Sánchez E. A decade of laparoscopic varicocelectomy: costs and learning stages. Archivos espanoles de urologia. 1999 Apr;52(3):245248.

12. Matsuda T, Horii Y, Higashi S, Oishi K, Takeuchi H, Yoshida O. Laparoscopic varicocelectomy: a simple technique for clip ligation of the spermatic vessels. The Journal of urology. 1992 Mar 1;147(3):636-638.

13. Shamsa A, Mohammadi L, Abolbashari M, Shakeri MT, Shamsa S. Comparison of open and laparoscopic varicocelectomies in terms of operative time, sperm parameters, and complications. Urology journal. 2009 Aug 20;6(3):170-175.

14. Watanabe M, Nagai A, Kusumi N, Tsuboi H, Nasu Y, Kumon $\mathrm{H}$. Minimal invasiveness and effectivity of subinguinal microscopic varicocelectomy: a comparative study with retroperitoneal high and laparoscopic approaches. International journal of urology. 2005 Oct;12(10):892-898.

15. Kočvara R, DvočÁček J, SedlÁček J, DÍT $`$ E ZE, NOVÁK KE. Lymphatic sparing laparoscopic varicocelectomy: a microsurgical repair. The Journal of urology. 2005 May;173(5):17511754 .

16. Al-Kandari AM, Shabaan H, Ibrahim HM, Elshebiny $\mathrm{YH}$, Shokeir AA. Comparison of outcomes of different varicocelectomy techniques: open inguinal, laparoscopic, and subinguinal microscopic varicocelectomy: a randomized clinical trial. Urology. 2007 Mar 1;69(3):417-420.

17. Osman T, El-Shourbagy A, Moustafa H, Maged W. Laparoscopic versus Open Retroperitoneal Bilateral Varix Ligation for Obese Patients Presenting with Primary Sub-Fertility: A Randomized Comparative Study. African Journal of Urology. 2004;10(1):50-57.

18. Podkamenev VV, Stalmakhovich VN, Urkov PS, Solovjev AA, Iljin VP. Laparoscopic surgery for pediatric varicoceles: randomized controlled trial. Journal of pediatric surgery. 2002 May 1;37(5):727-729.

19. Ogura K, Matsuda T, Terachi T, Horii Y, Takeuchi H, Yoshida O. Laparoscopic varicocelectomy: invasiveness and effectiveness compared with conventional open retroperitoneal high ligation. International Journal of Urology. 1994 Mar;1(1):62-66. 